\title{
Analysis of the Effect of the Friction Coefficient on a Pavement Structure
}

\author{
Lu Bai $\mathbb{D}^{1}$ and Yong-sheng Zhang $\mathbb{D}^{2}$ \\ ${ }^{1}$ School of Civil Engineering, Xuchang University, Xuchang 461000, China \\ ${ }^{2}$ China Academy of Transportation Science, Beijing 100029, China \\ Correspondence should be addressed to Lu Bai; lubai526@126.com
}

Received 20 September 2021; Revised 25 January 2022; Accepted 31 January 2022; Published 27 February 2022

Academic Editor: Yongsheng Yao

Copyright (c) 2022 Lu Bai and Yong-sheng Zhang. This is an open access article distributed under the Creative Commons Attribution License, which permits unrestricted use, distribution, and reproduction in any medium, provided the original work is properly cited.

\begin{abstract}
Insufficient skid resistance of pavement is one of the main causes of traffic accidents. In this study, the influence of the friction coefficient on the internal effect of the pavement structure is studied deeply by establishing the asymmetric finite element numerical model. The model analyzes the inner stress, strain, and displacement variations of the pavement, with friction coefficients under the conditions of $0.3,0.5,0.8$, and 1.0 and the action of the nonlinear superposition between the single-point static vertical load and horizontal load. In addition, against the limitations of the scatter calculation results, this paper analyzes the distribution of the internal stress field and displacement field. The results show that, with the attenuation of the friction coefficient, the distribution law of stress, strain, and displacement on the road surface $(Z=0)$ remains unchanged, and the maximum principal strain and the third principal strain on the $Z$-axis decrease monotonically with increasing depth. With the attenuation of the friction coefficient, the horizontal displacement inside the pavement structure gradually decreases, the vertical displacement changes insignificantly, and the principal stress gradually decreases. The principal strain and maximum shear stress inside the pavement structure show different changing rules.
\end{abstract}

\section{Introduction}

The friction coefficient between a tire and a road surface is an important indicator for evaluating the antiskid performance of the road surface. This is the main factor affecting the friction performance of the tread and the road surface. It is also an important factor affecting the safety of road traffic $[1-3]$. With the cumulative action of loading and the continuous influence of temperature and humidity, the friction coefficient between the pavement and tire decreases gradually $[4,5]$, which will cause a change in the internal stress of the pavement structure. At present, the friction contact model between the tread and the road surface is established and numerically analyzed, and it is obtained that, in the full acceleration slip state, the greater the friction coefficient, the greater the contact stress $[6,7]$, but when the friction coefficient exceeds a certain critical value, with the increase of its value, the antiskid performance in the braking state is no longer improved, and the compressive stress of the road surface increases significantly [8]. Anupam et al. [9] studied the variation law of antiskid performance with ambient temperature and road surface temperature and proposed the relationship between slider resistance and different parameters. $\mathrm{Li}$ [10] used the simulation test to explore the relationship between tire-sand surface contact and antiskid performance and evaluated the durability of antiskid performance from the perspective of tire-tread contact occlusion. Guo [11] established a three-dimensional finite element model of the truck tire, asphalt pavement structure, and pavement changing temperature field for truck tires with longitudinal patterns and highly nonlinear characteristics and predicted the dynamic response law of the asphalt pavement structure under complex heavy loads. Hao [12] established a refined finite element model and found that the effect of pattern distribution on the stress distribution state is smaller. Yao et al. [13] used the developed DEM model to 
accurately predict the mechanical properties and deformation behavior of SRM. Li et al. [14] carried out 2D finite element simulation of flexible pavement under half-sine load and established a numerical prediction method for flexible pavement dynamic characteristics considering the stress sensitivity and humidity change of subgrade soil.

Previous studies indicated that differences in the surface roughness may result in different results about internal force of the pavement structure [15-17]. However, relevant research on the influence of friction coefficient attenuation on the internal force of pavement structures under the action of nonlinear superposition between vertical and horizontal loads is lacking. By establishing a finite element model, this paper analyzes the inner stress, strain, and displacement variations of the pavement structure under different friction coefficients, explores the change in the internal force of pavement with the attenuation of the friction coefficient, and provides a reference for the design of the pavement structure and its antiskid performance.

\section{Mechanical Analysis Model}

In existing pavement structure analyses [18, 19], the linear superposition method is adopted for the analysis of the force state under the simultaneous action of vertical load and horizontal load. However, when the two act at the same time, it should be a coupled state, that is, a nonlinear superposition. Assuming that the contact surface between the wheel and the road is circular, the analysis is carried out according to the single-wheel load model. Under small deformation conditions, assuming that the pavement structure bears the vertical load, the load is evenly distributed in a circular area with a diameter of $2 \mathrm{a}(a=10.65 \mathrm{~cm})$. As shown in Figure 1, the corresponding friction load is $\mathrm{P}_{0}$. The coordinate system is established, as shown in Figure 2.

The vehicle is moving at a constant speed $v$, and the formula for the vertical force is as follows:

$$
F=F_{0} H(a-r) \delta(x-v t) \delta(y)=F(a, r, x, y, t),
$$

where $r=\sqrt{(x-v t)^{2}+y^{2}}, \delta(\bullet)$ is Dirac Delta functions, and $H(\bullet)$ is load action density. be

Therefore, the horizontally distributed load is assumed to

$$
P=P_{0} H(a-r) \delta(x-v t) \delta(y)
$$

where $P_{0}=\mu F_{0}$ and $\mu$ is the dynamic friction coefficient.

\section{Establish Governing Equations for Related Issues}

Under the combined action of horizontal load and vertical load, the mechanical model of the pavement structure is an asymmetric semi-infinite body or an asymmetric layered semi-infinite body. Therefore, the governing equation of the problem in the cylindrical coordinate system can be established [20]. The equilibrium differential equation is shown in equation (3), which is the
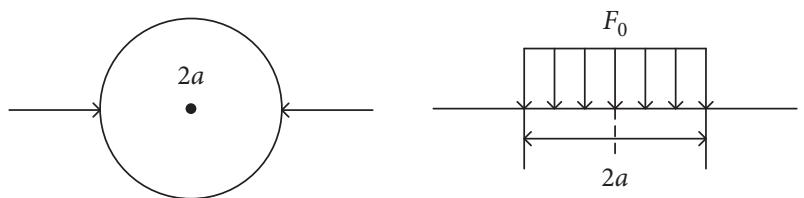

FIgURE 1: Schematic diagram of the vertical load borne by the pavement.
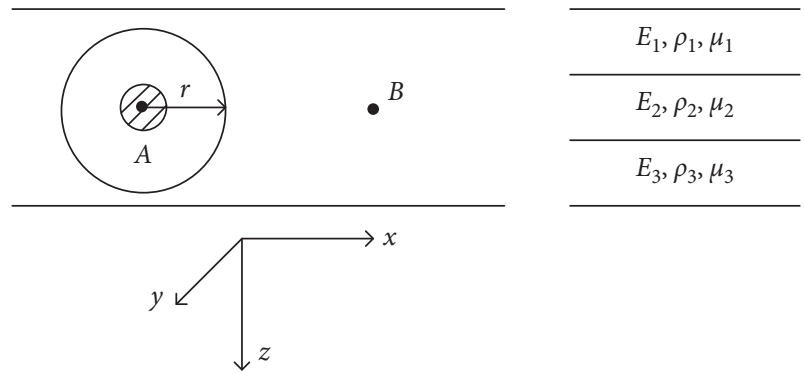

Figure 2: Coordinate system for analysis.

equilibrium differential equation of the pavement structure under nonaxisymmetric problems; the relationship between strain and displacement is shown in equation (4). The physical relationship of pavement materials obeys a generalized Hooke's law, and the Goodman model is used under the boundary conditions to characterize the state of interlayer bonding. The general formula of the boundary conditions for nonaxisymmetric subjects can be obtained as equation (5):

$\left\{\begin{array}{l}\frac{\partial \sigma_{r}}{\partial r}+\frac{1}{r} \frac{\partial \tau_{r \theta}}{\partial \theta}+\frac{\partial \tau_{r z}}{\partial z}+\frac{\sigma_{r}-\sigma_{\theta}}{r}=\rho \frac{\partial^{2} u}{\partial t^{2}} \\ \frac{\partial \tau_{r \theta}}{\partial r}+\frac{1}{r} \frac{\partial \sigma_{\theta}}{\partial \theta}+\frac{\partial \tau_{\theta z}}{\partial z}+\frac{2}{r} \tau_{r \theta}=\rho \frac{\partial^{2} v}{\partial t^{2}} \\ \frac{\partial \tau_{r z}}{\partial r}+\frac{1}{r} \frac{\partial \tau_{\theta z}}{\partial \theta}+\frac{\partial \sigma_{z}}{\partial z}+\frac{\tau_{r z}}{r}=\rho \frac{\partial^{2} w}{\partial t^{2}}\end{array}\right.$

$\left\{\begin{array}{l}\xi_{r}=\frac{\partial u}{\partial r} \\ \xi_{\theta}=\frac{u}{r}+\frac{1}{r} \frac{\partial v}{\partial \theta} \\ \xi_{z}=\frac{\partial w}{\partial z} \\ \gamma_{r \theta}=\frac{1}{r} \frac{\partial u}{\partial \theta}+\frac{\partial v}{\partial r}-\frac{v}{r} \\ \gamma_{\theta z}=\frac{1}{r} \frac{\partial w}{\partial \theta}+\frac{\partial v}{\partial z} \\ \gamma_{r z}=\frac{\partial u}{\partial z}+\frac{\partial w}{\partial r}\end{array}\right.$, 


$$
\left\{\begin{array}{l}
\left.\sigma_{z_{i}}\right|_{z=H_{i}}=\left.\sigma_{z_{i+1}}\right|_{z=H_{i}} \mid \\
\left.\tau_{\theta z_{i}}\right|_{z=H_{i}}=\left.\tau_{\theta z_{i+1}}\right|_{z=H_{i}} \\
\left.\tau_{r z_{i}}\right|_{z=H_{i}}=\left.\tau_{r z_{i+1}}\right|_{z=H_{i}} \\
\left.\tau_{\theta z_{i}}\right|_{z=H_{i}}=\left.K_{i}\left(v_{i+1}-v_{i}\right)\right|_{z=H_{i}} \\
\left.\tau_{r z_{i}}\right|_{z=H_{i}}=\left.K_{i}\left(u_{i+1}-u_{i}\right)\right|_{z=H_{i}} \\
\left.w_{i}\right|_{z=H_{i}}=\left.w_{i+1}\right|_{z=H_{i}}
\end{array}\right.
$$

where $K$ is the interlayer adhesion coefficient, $0<\mathrm{K}<\infty$.

The transfer matrix method is used to solve the governing equations under the action of static load and the nonlinear superposition of horizontal load and vertical load. The boundary conditions of vertical load $\mu F$ and horizontal load $\mathrm{F}$ are

(1) At $z=0$,

$$
\begin{gathered}
\left.\tau_{\theta z}\right|_{z=0}=\left.\mu F \sin \theta \overline{\tau_{\theta z}}\right|_{z=0}=\frac{\mu F_{0}}{\pi \delta} \times \frac{J_{1}(\xi \delta)}{\xi} \sin \theta, \\
\left.\tau_{r z}\right|_{z=0}=-\left.\mu F \cos \theta \overline{\tau_{r z}}\right|_{z=0}=\frac{\mu F_{0}}{\pi \delta} \times \frac{J_{1}(\xi \delta)}{\xi} \cos \theta, \\
\bar{F}(\xi)=\frac{F_{0}}{\pi \delta} \times \frac{J_{1}(\xi \delta)}{\xi} \overline{\sigma_{z}}(\xi, 0)=\frac{F_{0}}{\pi \delta} \times \frac{J_{1}(\xi r)}{\xi} .
\end{gathered}
$$

(2) At $z=\infty$, for the Goodman model, when $\tau=\kappa \Delta u(0$ $<\kappa<\infty), k \longrightarrow \infty$, the interface completely continuous boundary condition can be written as

$$
\begin{aligned}
& \left.\left(\bar{\tau}_{\theta z_{1}}+\bar{\tau}_{r z_{1}}\right)\right|_{z=0}=0 \\
& \left.\left(\bar{\tau}_{\theta z_{1}}-\bar{\tau}_{r z_{1}}\right)\right|_{z=0}=\frac{2 \mu F_{0}}{\pi \delta} \times \frac{J_{1}(\xi r)}{\xi}, \\
& \left.\left(\bar{\tau}_{\theta z_{i}}+\bar{\tau}_{r z_{i}}\right)\right|_{z=H_{i}}=\left.\left(\bar{\tau}_{\theta z_{i+1}}+\bar{\tau}_{r z_{i+1}}\right)\right|_{z=H_{i}}, \\
& \left.\left(\bar{\tau}_{\theta z_{i}}-\bar{\tau}_{r z_{i}}\right)\right|_{z=H_{i}}=\left.\left(\bar{\tau}_{\theta z_{i+1}}-\bar{\tau}_{r z_{i+1}}\right)\right|_{z=H_{i}}
\end{aligned}
$$

$\left.\frac{1}{K}\left(\bar{\tau}_{\theta z_{i}}+\bar{\tau}_{r z_{i}}+\bar{v}_{i}-\bar{u}_{i}\right)\right|_{z=H_{i}}=\left.\left(\bar{v}_{i+1}-\bar{u}_{i+1}\right)\right|_{z=H_{i}}$,

$$
\left.\bar{w}_{i}\right|_{z=H_{i}}=\left.\bar{w}_{i+1}\right|_{z=H_{i}}
$$

$$
\begin{aligned}
\sigma_{r} & =-\int_{0}^{\infty} \xi\left\{[A-(1+2 \mu-\xi z) B] e^{-\xi z}-[C+(1+2 \mu+\xi z) D] e^{\xi z}\right\} J_{1}(\xi r) \cos \theta \mathrm{d} \xi+\frac{1}{r} U_{2} \cos \theta, \\
\sigma_{\theta} & =2 \mu \int_{0}^{\infty} \xi\left\{B e^{-\xi z}+D e^{\xi z}\right\} J_{1}(\xi r) \cos \theta \mathrm{d} \xi-\frac{1}{r} U_{2} \cos \theta, \\
\sigma_{r} & =\int_{0}^{\infty} \xi\left\{[A+(1-2 \mu+\xi z) B] e^{-\xi z}-[C-(1-2 \mu-\xi z) D] e^{\xi z}\right\} J_{1}(\xi r) \cos \theta \mathrm{d} \xi, \\
\tau_{r \theta} & =\int_{0}^{\infty} \xi\left\{E e^{-\xi z}+F e^{\xi z}\right\} J_{1}(\xi r) \sin \theta \mathrm{d} \xi+\frac{1}{r} U_{2} \sin \theta, \\
\tau_{\theta z}= & \frac{1}{2}\left(H_{2}+H_{0}\right) \sin \theta, \\
\tau_{r z}= & \frac{1}{2}\left(H_{2}-H_{0}\right) \cos \theta .
\end{aligned}
$$

Displacement field is 


$$
\begin{aligned}
u & =-\frac{1+\mu}{2 E}\left(U_{2}-U_{0}\right) \cos \theta \\
v & =-\frac{1+\mu}{2 E}\left(U_{2}+U_{0}\right) \sin \theta \\
w & =-\frac{1+\mu}{2 E} \int_{0}^{\infty}\left\{[A+(2-4 \mu+\xi z) B] e^{-\xi z}+[C-(2-4 \mu-\xi z) D] e^{\xi z}\right\} J_{1}(\xi r) \cos \theta \mathrm{d} \xi \\
U_{2}= & \int_{0}^{\infty}\left\{[A-(1-\xi z) B-2 E] e^{-\xi z}-[C+(1+\xi z) D+2 F] e^{\xi z}\right\} J_{1}(\xi r) \mathrm{d} \xi \\
U_{0}= & \int_{0}^{\infty}\left\{[A-(1-\xi z) B-2 E] e^{-\xi z}-[C+(1+\xi z) D-2 F] e^{\xi z}\right\} J_{1}(\xi r) \mathrm{d} \xi \\
J_{0}(\xi r)= & \frac{2}{\xi r} J_{1}(\xi r)-J_{0}(\xi r) \mathrm{d} \xi . \\
H_{2}= & \int_{0}^{\infty} \xi\left\{[A-(2 \mu-\xi z) B-E] e^{-\xi z}+[C+(2 \mu+\xi z) D+F] e^{\xi z}\right\} J_{2}(\xi r) \mathrm{d} \xi \\
H_{0}= & \int_{0}^{\infty} \xi\left\{[A-(2 \mu-\xi z) B+E] e^{-\xi z}+[C+(2 \mu+\xi z) D-F] e^{\xi z}\right\} J_{0}(\xi r) \mathrm{d} \xi \\
& \\
&
\end{aligned}
$$

$\mathrm{A}, \mathrm{B}, \mathrm{C}, \mathrm{D}, \mathrm{E}$, and $\mathrm{F}$ are determined by boundary conditions.

\section{Calculation Structure of Stress Field and Displacement Field}

4.1. Displacement Field Distribution. Figure 3 is the horizontal displacement $U$ under different friction coefficient conditions. The result shows that, with the attenuation of the friction coefficient, the horizontal displacement $U$ inside the pavement structure gradually decreases, which is most obvious in the range affected by the load radius $(r=0 \sim 10.65 \mathrm{~cm})$.

Figure 4 is the vertical displacement $W$ under different friction coefficient conditions. The result shows that, as the friction coefficient decreases, the vertical displacement $W$ inside the pavement structure shows an overall increasing trend.

4.2. Stress Field Distribution. In Figures 5 and 6, it is seen that, with the attenuation of the friction coefficient, the maximum principal stress inside the pavement structure gradually decreases. The area, depth, and tensile stress value of the tension zone decrease within $20 \mathrm{~cm}$ from the surface of the load circle. The maximum shear stress inside the pavement structure in the load circle gradually decreases, but the influence range becomes larger.

4.3. Strain Field Distribution. In Figure 7, it is seen that, as the attenuation of the friction coefficient, the maximum principal strain inside the pavement structure in the load circle gradually decreases, but the influence range becomes larger.

\section{Analysis of Nonlinear Superposition of Static Vertical Load and Horizontal Load under Different Friction Coefficient Conditions}

The following conditions are used to calculate the internal stress, strain, and displacement of the structure: a single circular load with a radius of $10.65 \mathrm{~cm}$ on the surface of the elastic half-space body, a load concentration of $0.7 \mathrm{MPa}$, a friction coefficient of $0.3,0.5,0.8$, and 1.0 , respectively, halfspace body elastic modulus $E=1500 \mathrm{MPa}$, and Poisson's 


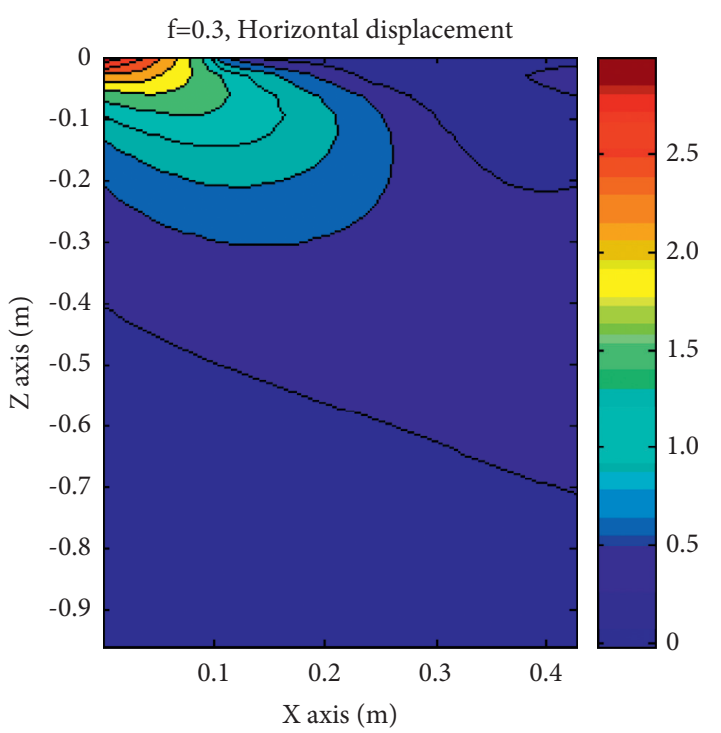

(a)

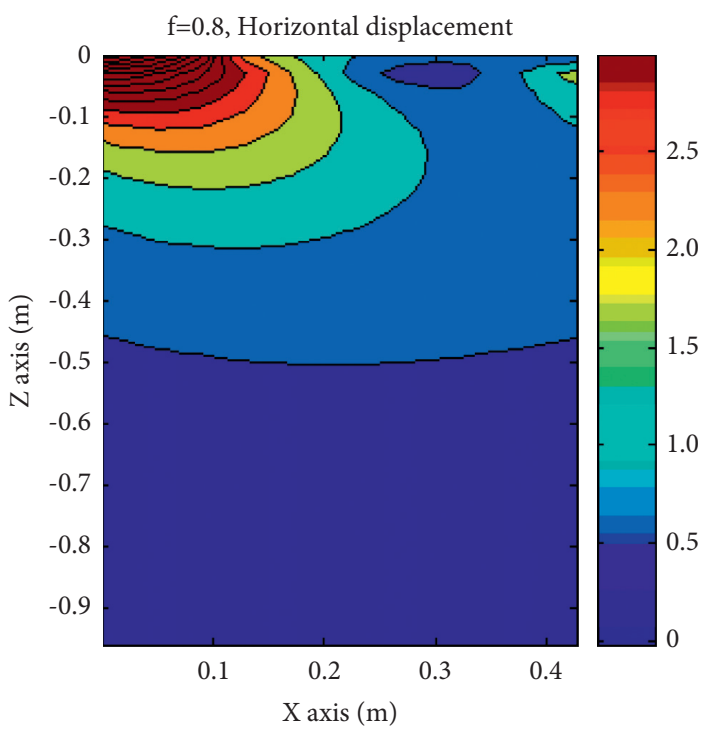

(c)

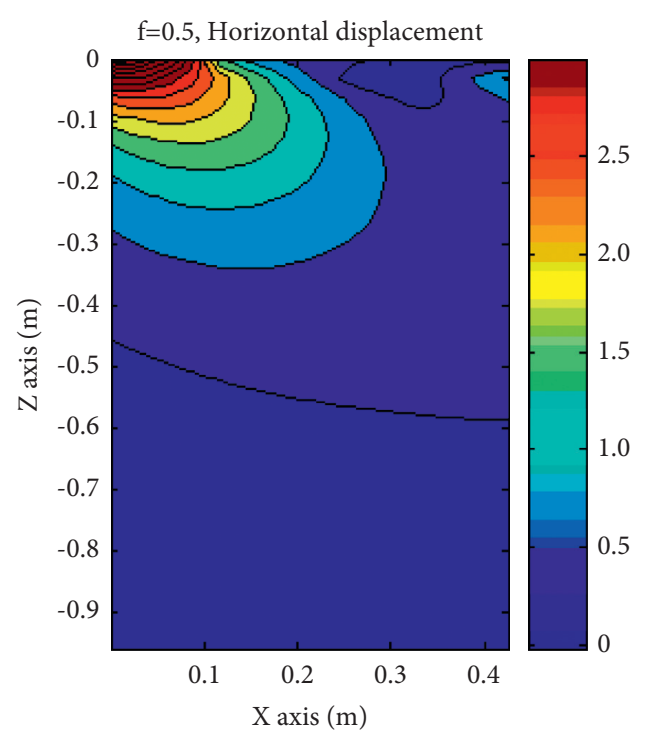

(b)

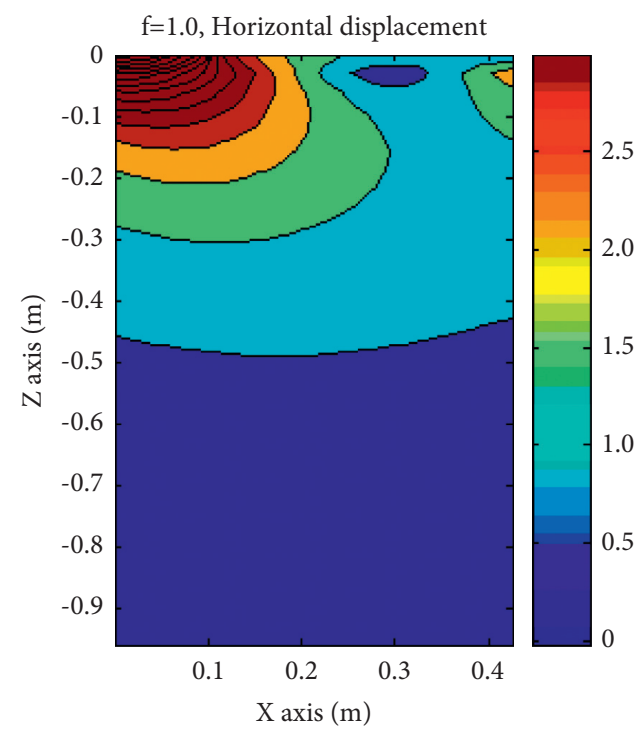

(d)

Figure 3: Horizontal displacement nephogram under different friction (f) coefficients. (a) $f=0.3$. (b) $f=0.5$. (c) $f=0.8$. (d) $f=1.0$.

ratio of 0.3 . In the horizontal direction ( $x$-axis), 10 points are calculated inside the load circle, 30 points are calculated outside the load circle, and 30 points are calculated in the vertical direction ( $z$-axis).

\subsection{The Calculated Value of Each Calculation Point on the} Surface $x$-Axis $(z=0)$. Under different friction coefficient conditions, when the horizontal load $(\mathrm{H})$ and the vertical load (V) are nonlinearly superimposed, the results of the stress, strain, and displacement of each calculation point on the $x$-axis $(z=0)$ of the calculated structure surface are shown in Figure 8.

Displacement changes: the horizontal displacement of each calculation point on the structure surface has the largest value at the center of the load circle, and this value decreases with the decrease of the friction coefficient, which is most obvious inside the load circle. This phenomenon shows that, along the direction of travel of the car (the positive direction of the $x$-axis), when the friction coefficient is attenuated, the horizontal displacement of the surface decreases, and the movement of the road surface weakens. As the friction 


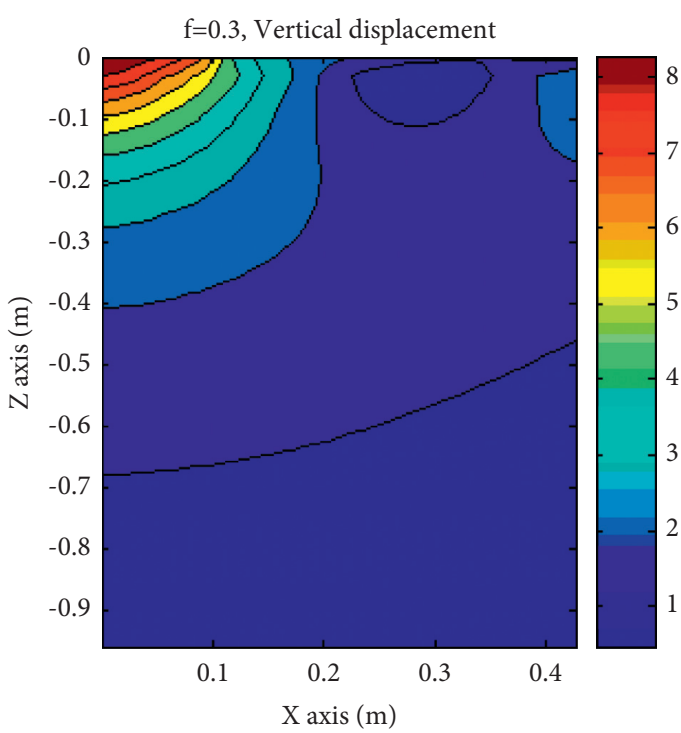

(a)

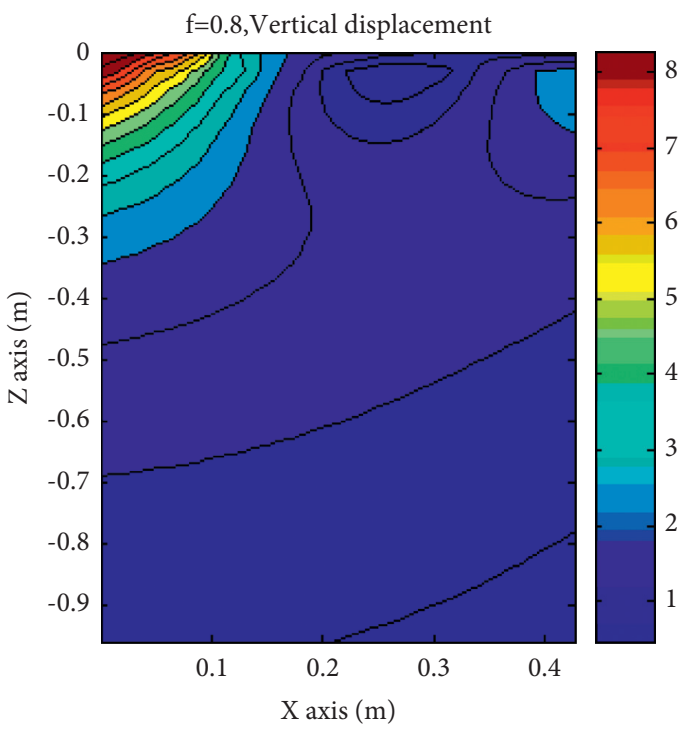

(c)

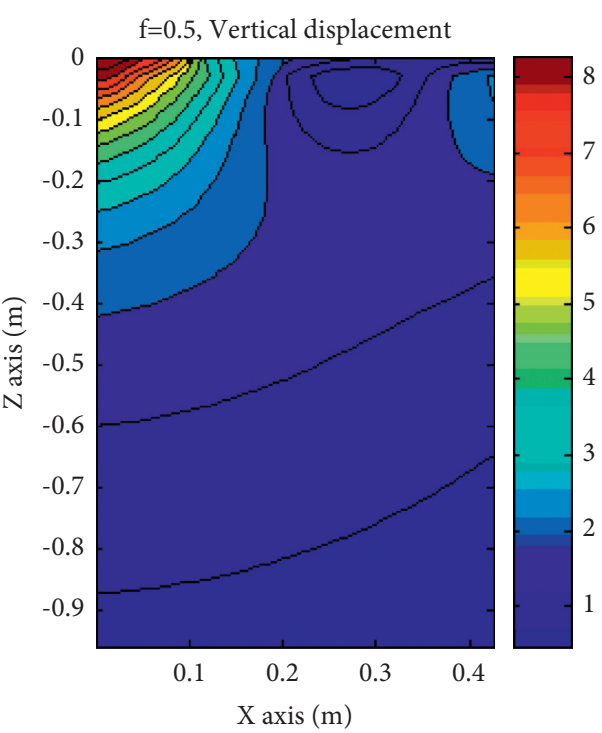

(b)

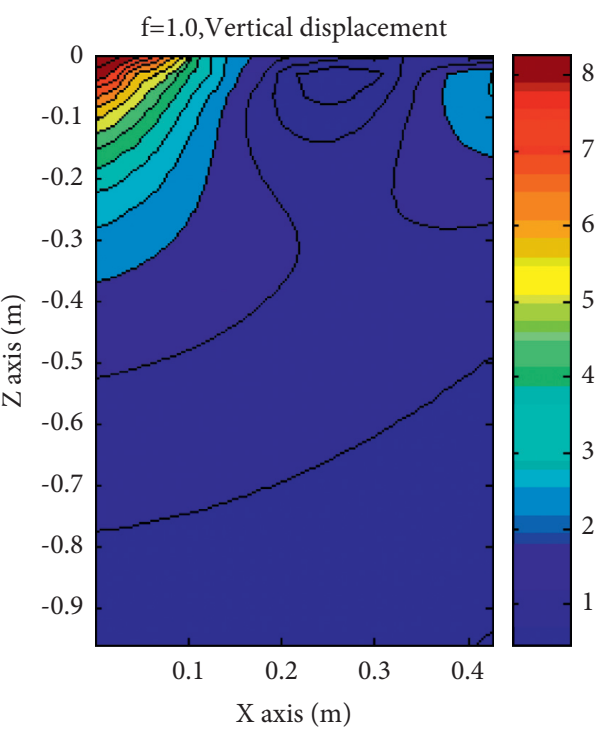

(d)

Figure 4: Vertical displacement nephogram under different friction coefficients. (a) $f=0.3$. (b) $f=0.5$. (c) $f=0.8$. (d) $f=1.0$.

coefficient decreases, the vertical displacement $W$ of each calculation point on the surface does not change significantly.

The stress analysis results are shown in Figures 9 and 10 (a) and 10(b). The normal stress curve in the $x$-direction shows that the normal stresses $\sigma_{x}$ and $\sigma_{y}$ on the $x$-axis have very similar trends to the principal stress curve. Inside the load circle, the maximum principal stress on the $x$-axis following the increase in $x$ gradually changes from compressive stress to tensile stress. The tensile stress value reaches the maximum at the edge of the load circle, and the value gradually increases with increasing horizontal load, while the tensile stress value outside the load circle gradually decreases to 0 . The third principal stress is mainly the compressive stress, and its value gradually decreases as the friction coefficient decreases; the value outside the load circle is close to 0 . The $z$-direction stress $\sigma_{z}$ of each calculation point on the $x$-axis does not change much in Figure 10(c), and the five curves under the condition of different friction coefficients completely overlap. This shows that the attenuation of the friction coefficient has no effect on the $z$-direction stress at each calculation point on the $x$-axis.

Inside the load circle, the shear stress $\tau_{z x}$ of each calculation point on the $x$-axis gradually decreases with the attenuation value of the friction coefficient and becomes 0 outside the load circle, as shown in Figure 10(d). Inside the load circle, the maximum shear stress gradually increases 


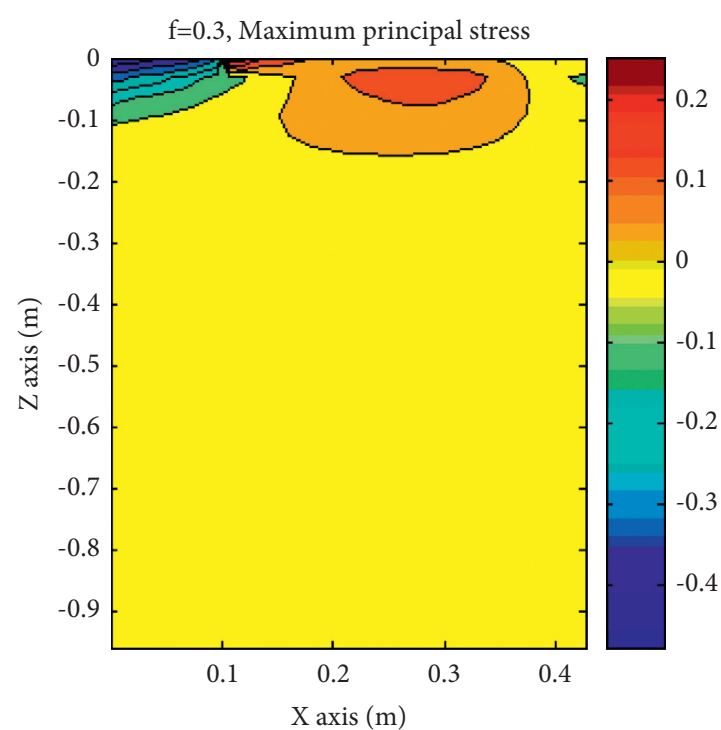

(a)

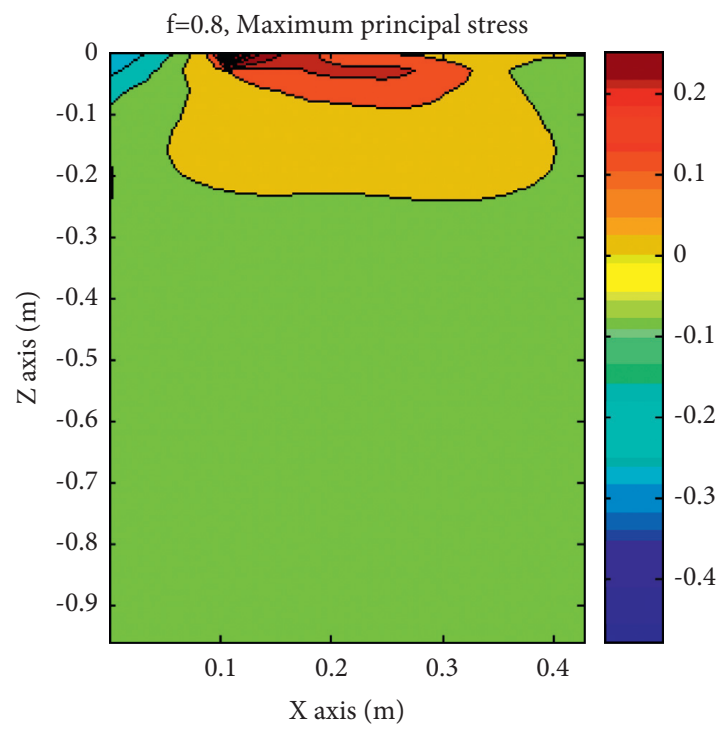

(c)

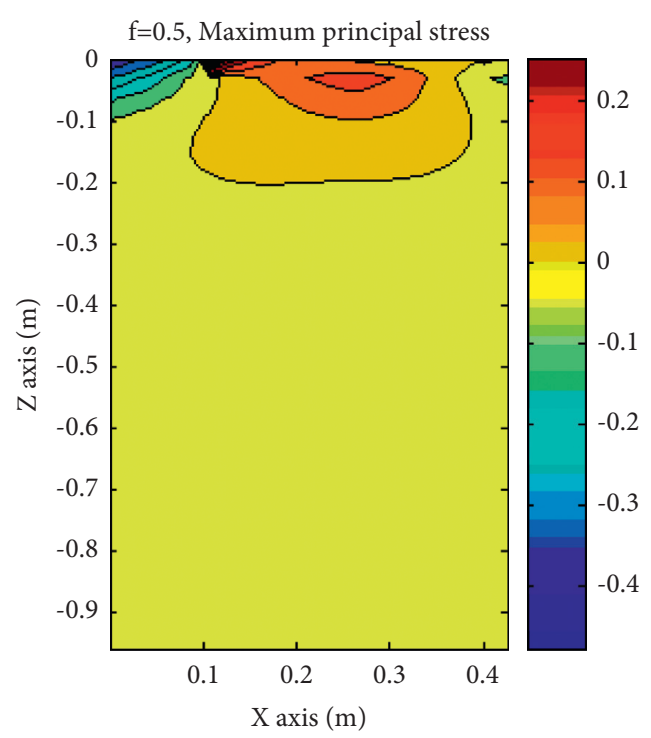

(b)

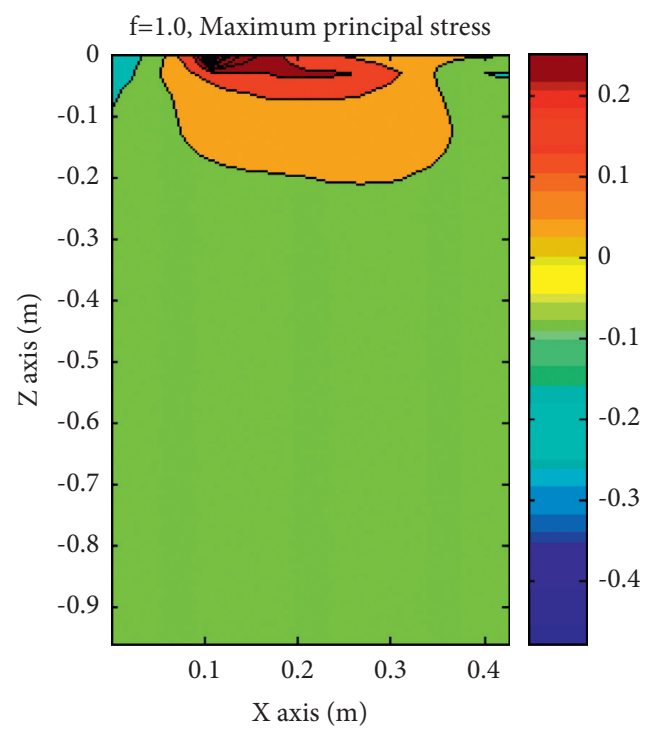

(d)

Figure 5: Maximum principal stress nephogram under different friction coefficients. (a) $f=0.3$. (b) $f=0.5$. (c) $f=0.8$. (d) $f=1.0$.

with increasing $x$, reaches the maximum value at the edge of the load circle, and gradually decreases as the friction coefficient attenuates, while the maximum shear stress value outside the load circle gradually decreases to 0 .

The variation in strain with the friction coefficient is shown in Figure 11. Inside the load circle, the maximum principal strain on the $x$-axis gradually changes from compressive strain to tensile strain as $x$ increases. The tensile strain value reaches the maximum at the edge of the load circle and gradually decreases as the friction coefficient decays, while the tensile strain value outside the load circle gradually decreases to zero. The third principal strain is all compressive strain. The value inside the load circle is very large, and its value gradually decreases with the attenuation of the friction coefficient; the value outside the load circle is close to zero. This is the same as the law of stress change.

5.2. The Calculated Value of Each Calculation Point on the $z$ Axis $(x=0)$ of the Load Center Axis of the Single Circle. Under different friction coefficient conditions, when the horizontal load and vertical load are nonlinearly superimposed, the calculation results of the stress, strain, and displacement at each calculation point on the central axis $Z$ $(x=0)$ of the single circular load of the above calculation structure are shown in Figure 12. With the attenuation of the 


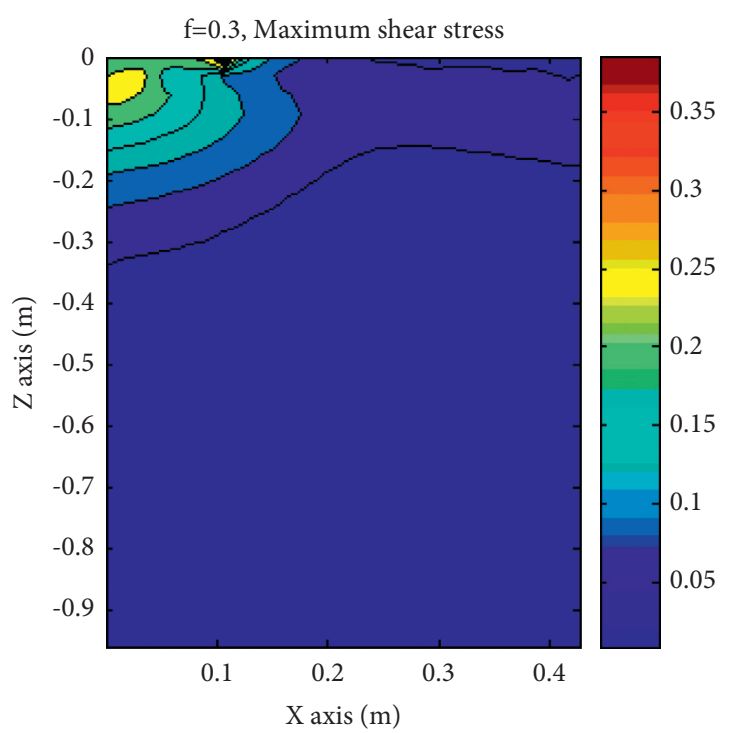

(a)

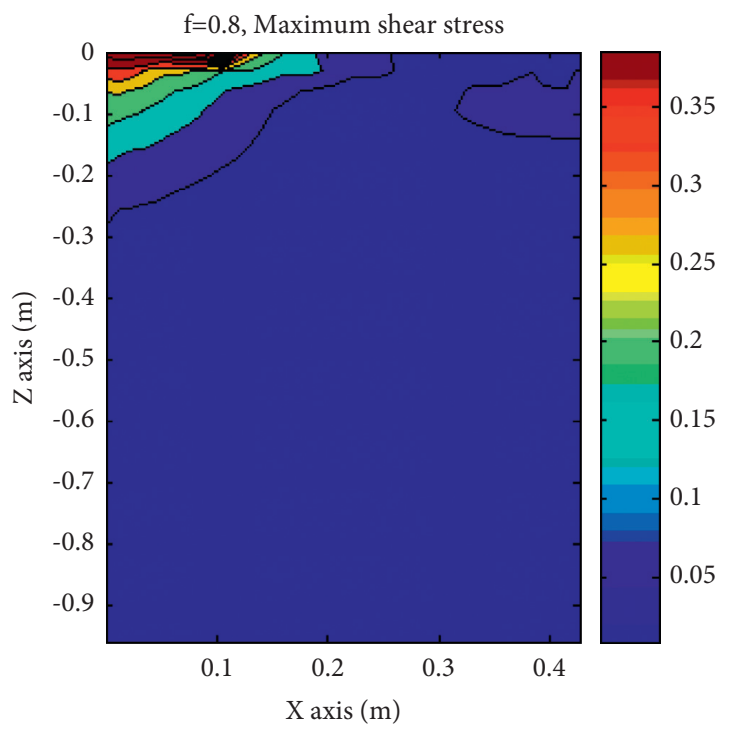

(c)

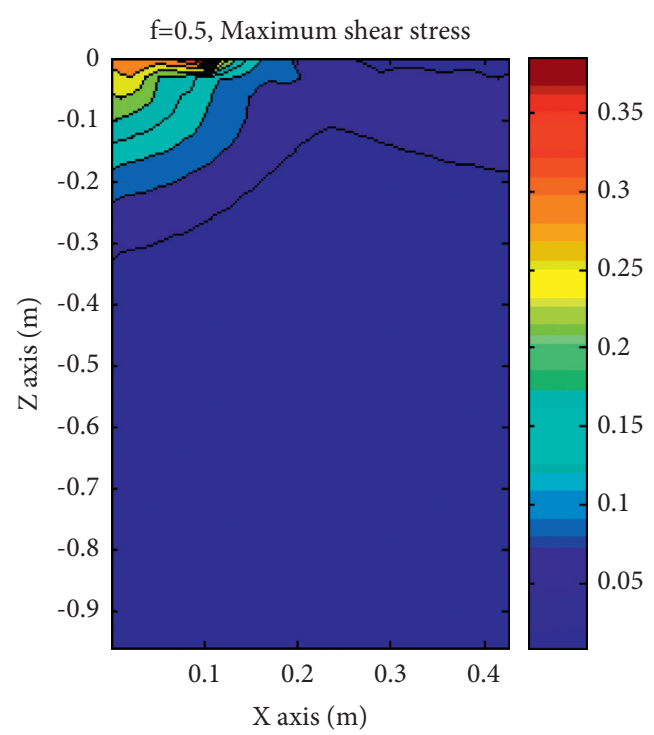

(b)

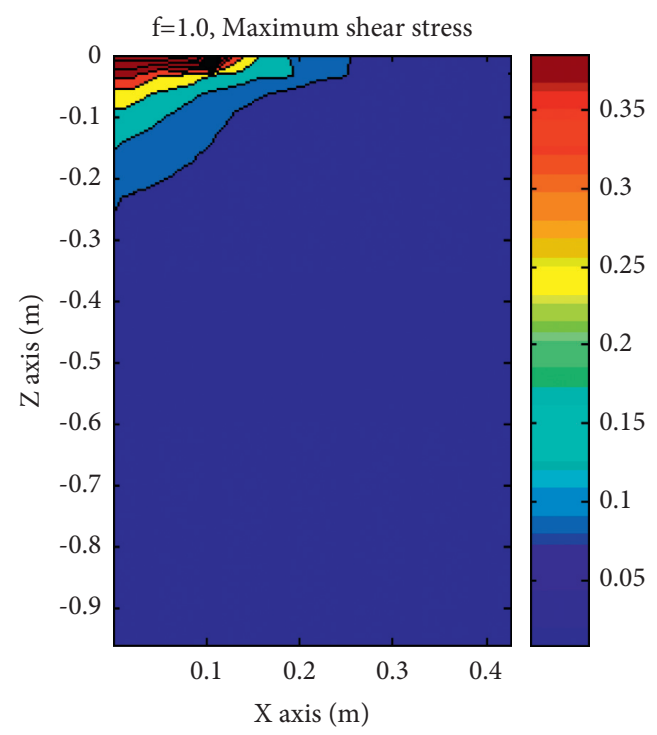

(d)

Figure 6: Maximum shear stress nephogram under different friction coefficients. (a) $f=0.3$. (b) $f=0.5$. (c) $f=0.8$. (d) $f=1.0$.

friction coefficient, the horizontal displacement on the $z$-axis gradually decreases, and the vertical displacement remains unchanged.

In Figures 13 and 14, it is seen that the normal stress curve in the $x$-direction shows that the stress $\sigma_{x}$ on the $z$-axis is very similar to the principal stress. It appears as a compressive stress zone in the range of $0-115 \mathrm{~cm}$ and becomes tensile stress in the range of $15 \mathrm{~cm}-40 \mathrm{~cm}$. The position of the maximum tensile stress appears at a depth of approximately $20 \mathrm{~cm}$, and the maximum principal stress value below $40 \mathrm{~cm}$ is already very small, approximate to zero. In the compressive stress region, with the decay of the friction coefficient, the maximum principal stress on the $z$-axis gradually increases, while in the tensile stress region, it is the opposite; at the same time, with the decay of the friction coefficient, the normal stresses $\sigma \mathrm{y}$ and $\sigma \mathrm{z}$ are on the $z$-axis The value does not change much, while the shear stress $\tau \mathrm{zx}$ decreases gradually. When the friction coefficient $f=0$ or 0.3 , the maximum shear stress on the $z$-axis shows a trend of first increasing and then decreasing with increasing depth. The peak value of the maximum shear stress appears within a range of approximately $10 \mathrm{~cm}$ from the surface, and as the friction coefficient decreases, the maximum shear stress value decreases. When the friction coefficient $f=0.5,0.8$, or 


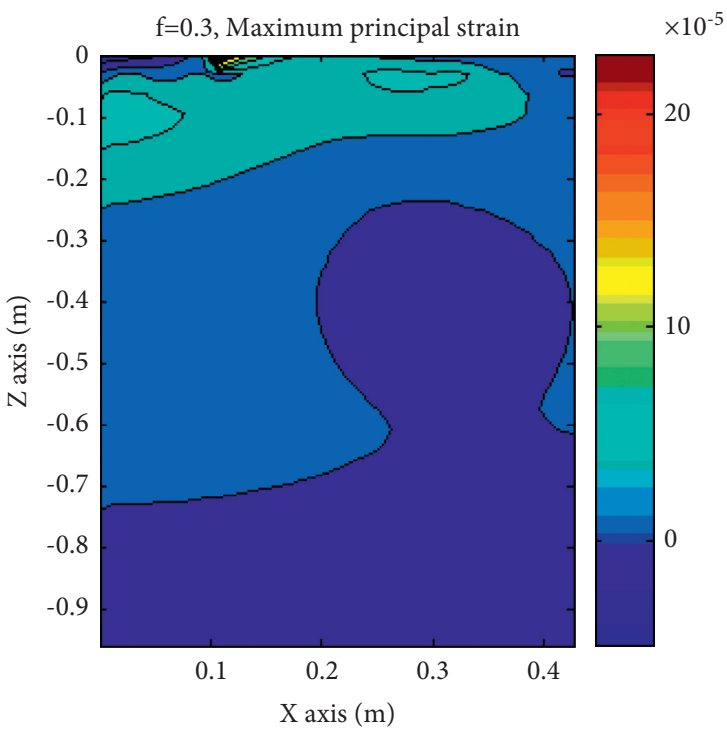

(a)

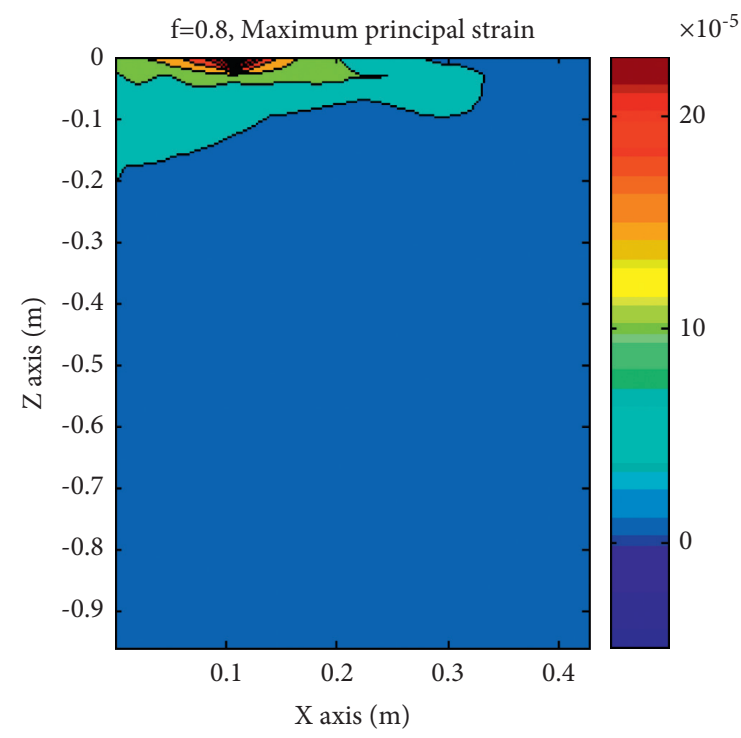

(c)

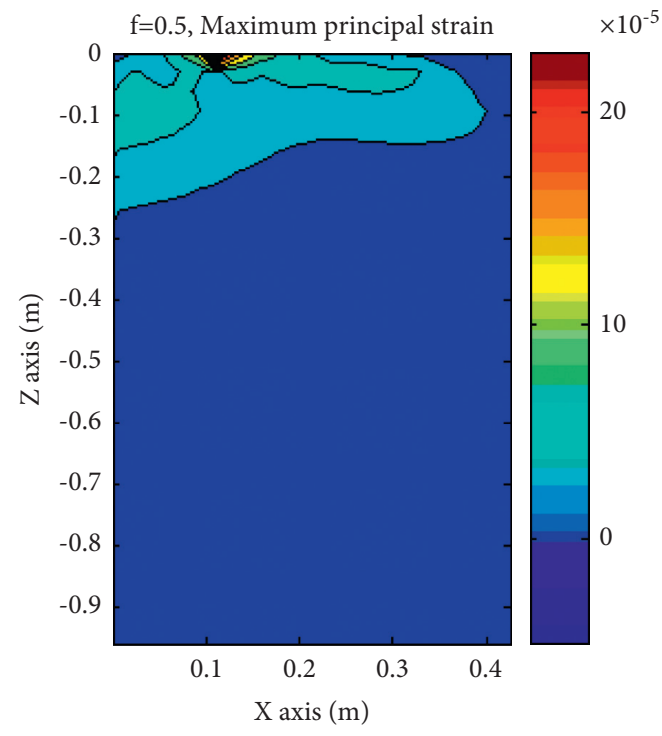

(b)

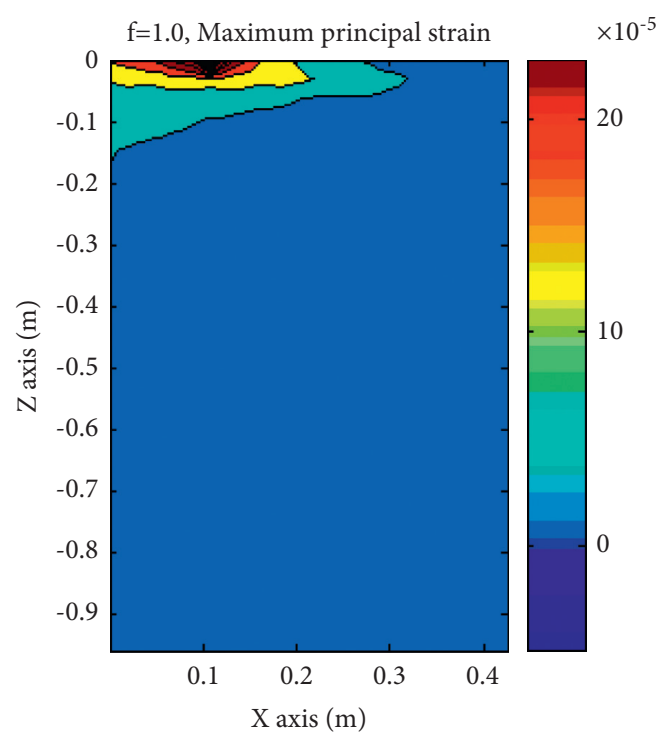

(d)

Figure 7: Maximum principal strain nephogram under different friction coefficients. (a) $f=0.3$. (b) $f=0.5$. (c) $f=0.8$. (d) $f=1.0$.

1.0 , the maximum shear stress on the $z$-axis shows a monotonic decrease with increasing depth. The maximum shear stress peaks when the surface $z=0$ and decreases with the attenuation of the friction coefficient.

The maximum principal strain curve in Figure 15(a) shows that when the friction coefficient $f=0$ or 0.3 , the maximum principal strain on the $z$-axis gradually changes from compressive strain to tensile strain as the depth increases. The range of $0 \sim 5 \mathrm{~cm}$ is the compressive strain zone, $5 \mathrm{~cm}$ below is the tensile strain zone, and the maximum tensile strain peaks at $10 \mathrm{~cm}$ from the surface. When the friction coefficient $f=0.5$, the maximum principal strain on the $z$-axis is mainly tensile strain, and the value first increases and then decreases with increasing depth. The maximum tensile strain peak appears at a position approximately $10 \mathrm{~cm}$ from the surface. When the friction coefficient $f=0.8$ or 1.0 , the maximum principal strain on the $z$-axis decreases monotonically with increasing depth. The peak of the maximum tensile strain appears on the surface, and the value of the maximum principal strain increases with increasing horizontal load.

It can be seen in Figure 15(b) that the third principal strain is compressive strain, where when the friction coefficient $f=0$ or 0.3 , the third principal strain on the $z$-axis shows a trend of first increasing and then decreasing with the increase of depth, and the peaks are at $5 \mathrm{~cm}$ away from 


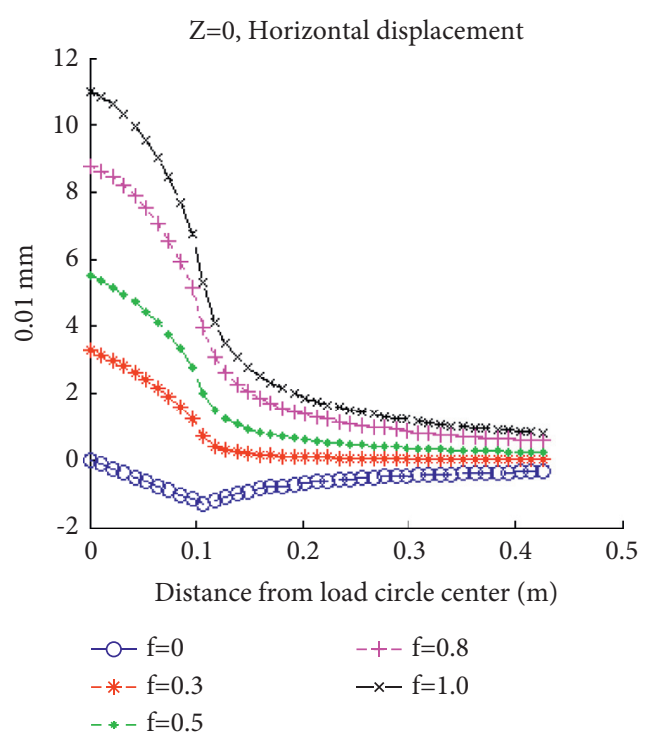

(a)

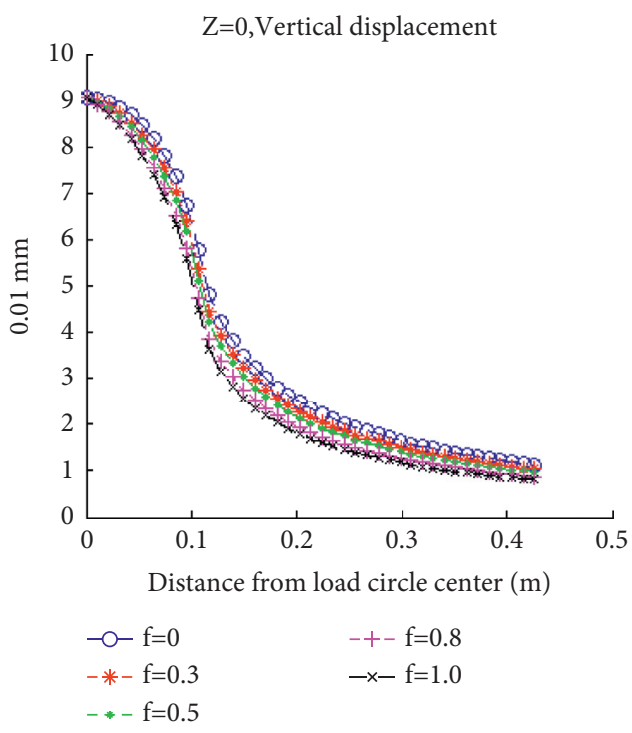

(b)

Figure 8: $x$-axis $(z=0)$ displacement calculation results of structure. (a) Calculation results of horizontal displacement of structure in $x$-axis $(z=0)$. (b) Calculation results of vertical displacement of structure in $x$-axis $(z=0)$.

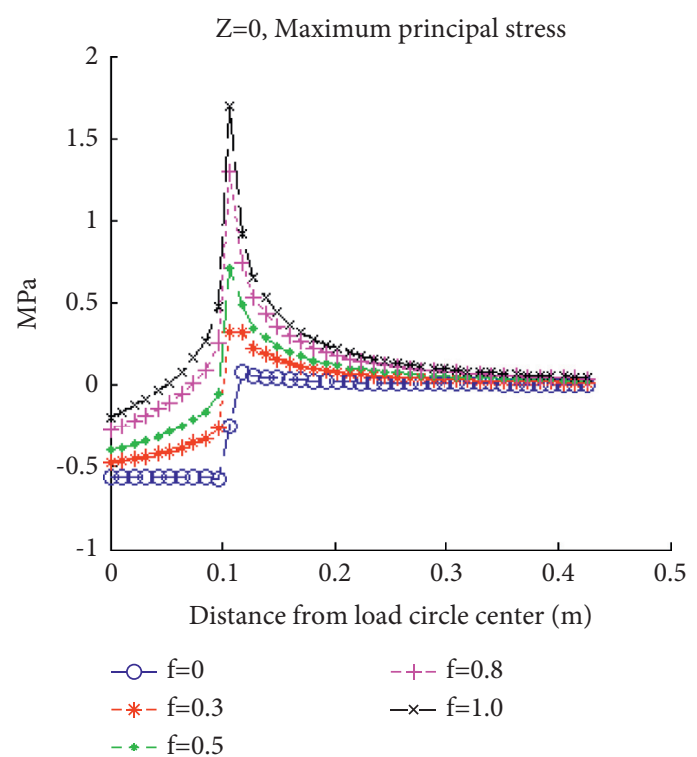

(a)

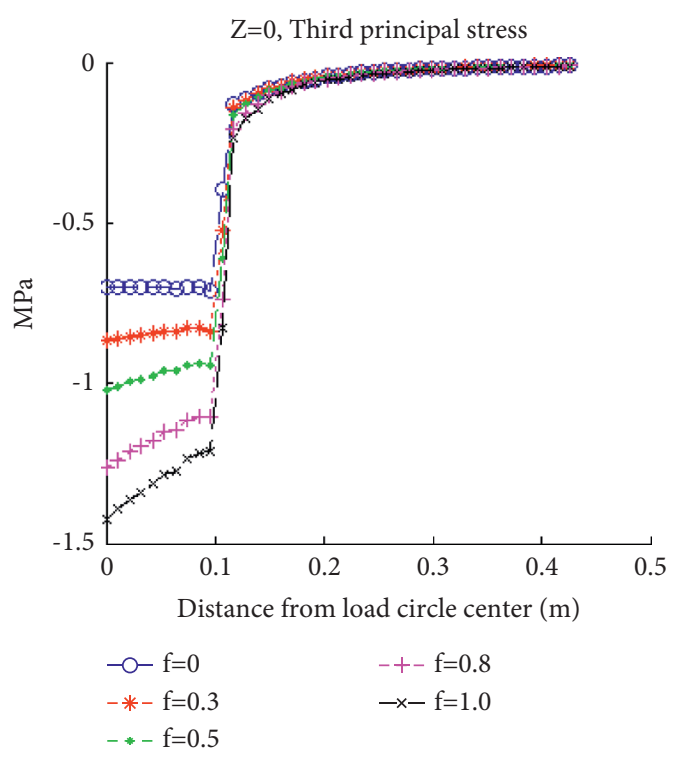

(b)

Figure 9: Continued. 


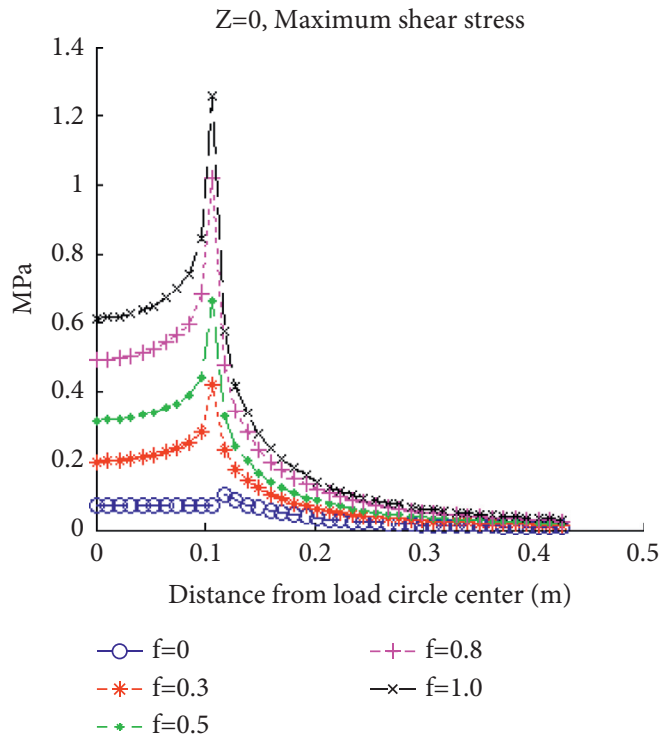

(c)

FIGURE 9: Calculation results of principal stress of structure in $x$-axis $(z=0)$. (a) Calculation results of maximum principal stress of structure in $x$-axis $(z=0)$. (b) Calculation results of third principal stress of structure in $x$-axis $(z=0)$. (c) Calculation results of maximum shear stress of structure in $x$-axis $(z=0)$.

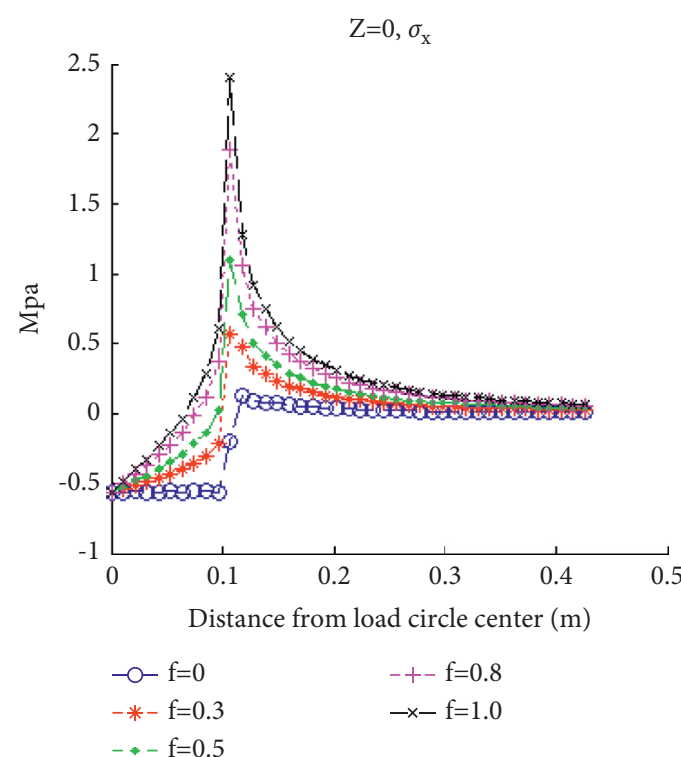

(a)

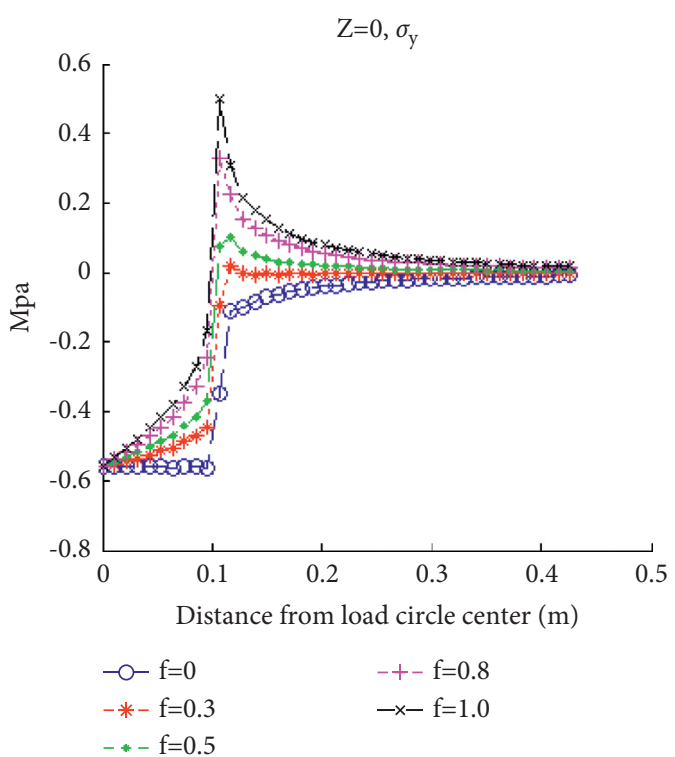

(b)

Figure 10: Continued. 


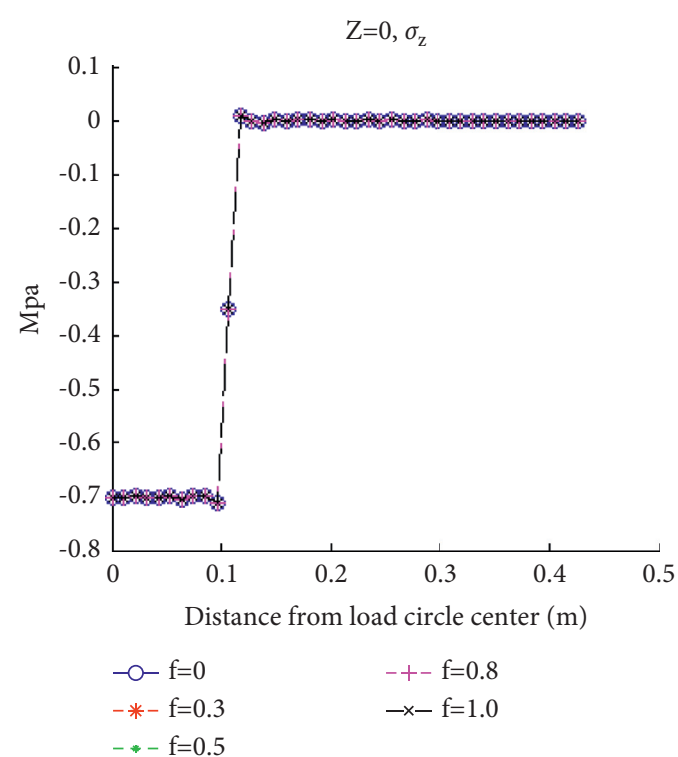

(c)

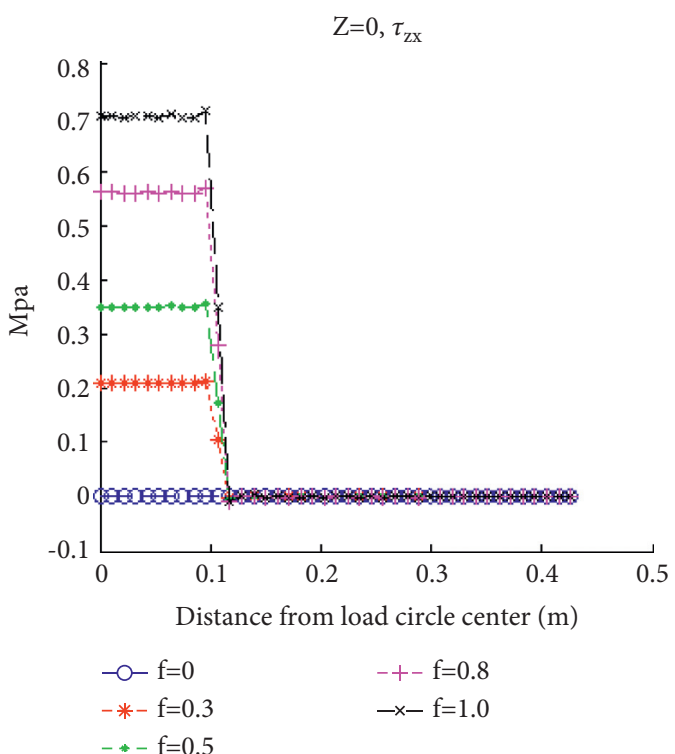

(d)

Figure 10: Calculation results of normal stress and shear stress of structure in $x$-axis $(z=0)$. (a) Calculation results of normal stress $\sigma_{x}$ of structure in $x$-axis $(z=0)$. (b) Calculation results of normal stress $\sigma_{y}$ of structure in $x$-axis $(z=0)$. (c) Calculation results of normal stress $\sigma_{Z}$ of structure in $x$-axis $(z=0)$. (d) Calculation results of shear stress $\tau_{z x}$ of structure in $x$-axis $(z=0)$.

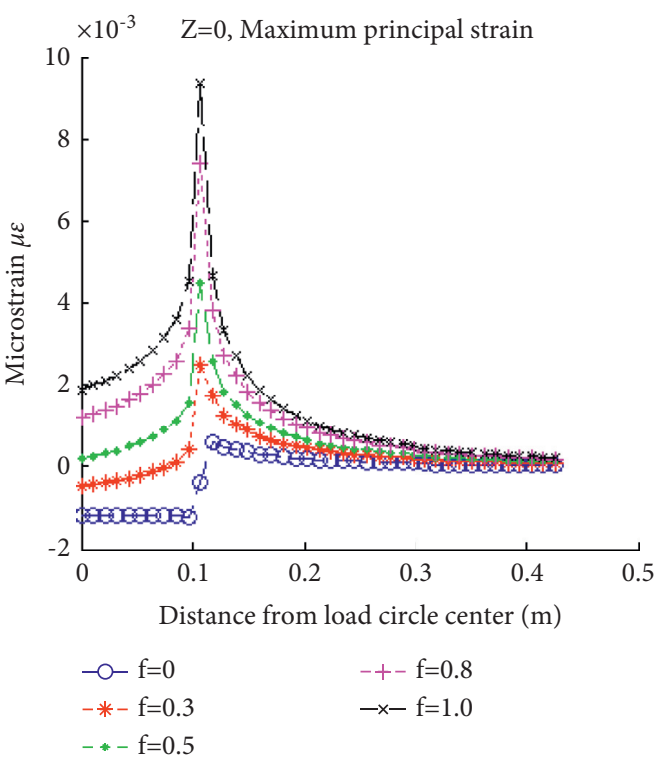

(a)

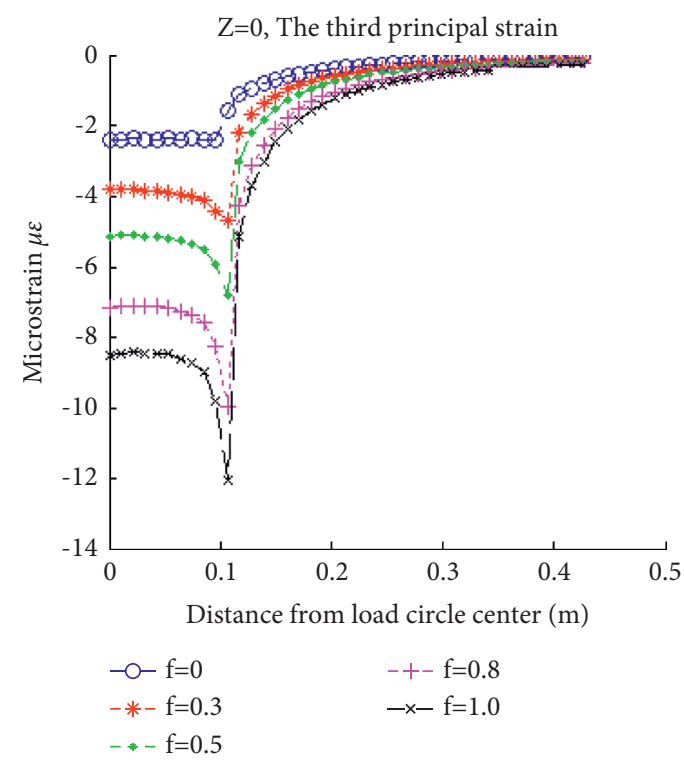

(b)

Figure 11: Calculation results of principal strain of structure in $x$-axis $(z=0)$. (a) Calculation results of maximum principal strain of structure in $x$-axis $(z=0)$. (b) Calculation results of third principal strain of structure in $x$-axis $(z=0)$.

the surface. When the friction coefficient $f=0.5,0.8$, or 1.0 , the third principal strain on the $z$-axis decreases monotonically with increasing depth, the peak value of the third principal strain appears on the surface, and the value of the third principal strain increases with increasing friction coefficient. 


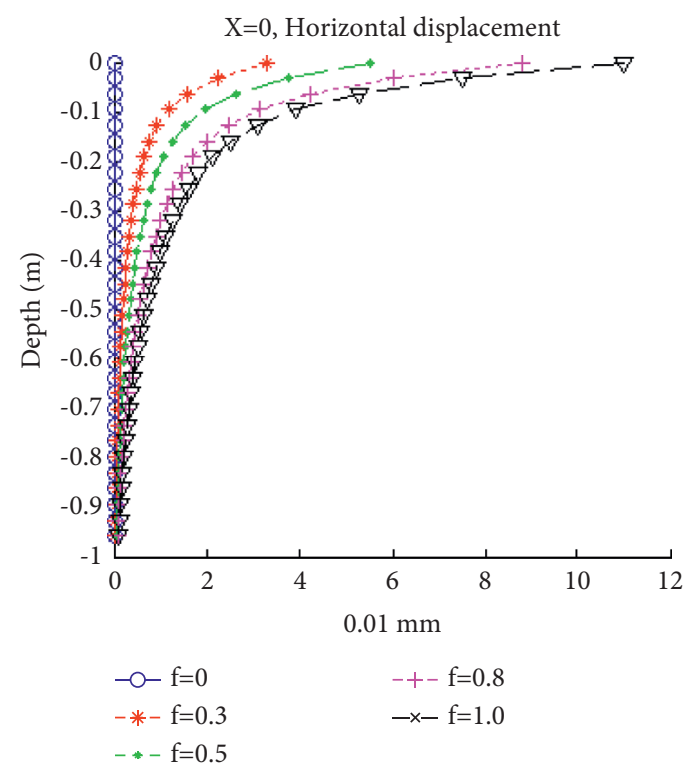

(a)

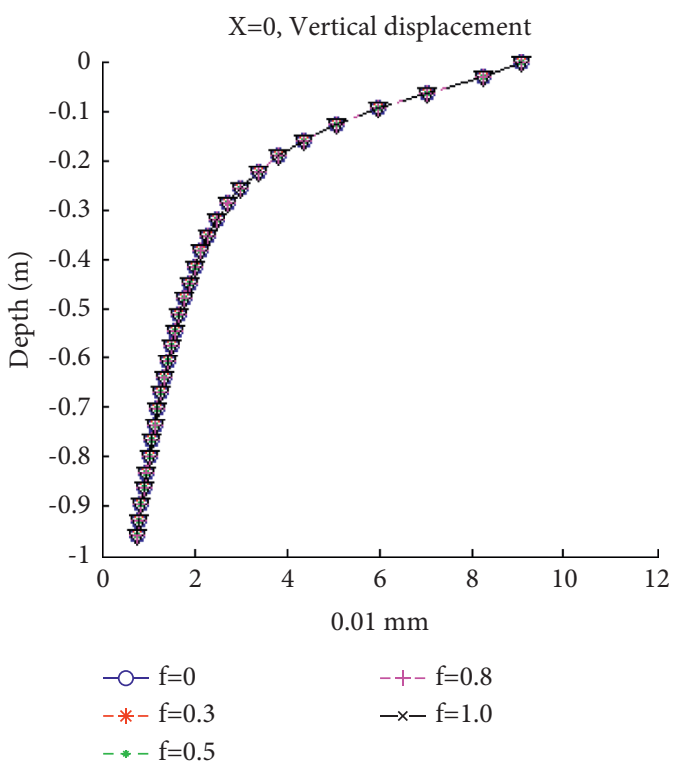

(b)

Figure 12: Calculation result of center point displacement of single circular load in $z$-axis $(x=0)$. (a) Calculation result of center point horizontal displacement of single circular load in $z$-axis $(x=0)$. (b) Calculation result of center point vertical displacement of single circular load in $z$-axis $(x=0)$.

$\mathrm{X}=0$, Maximum principal stress

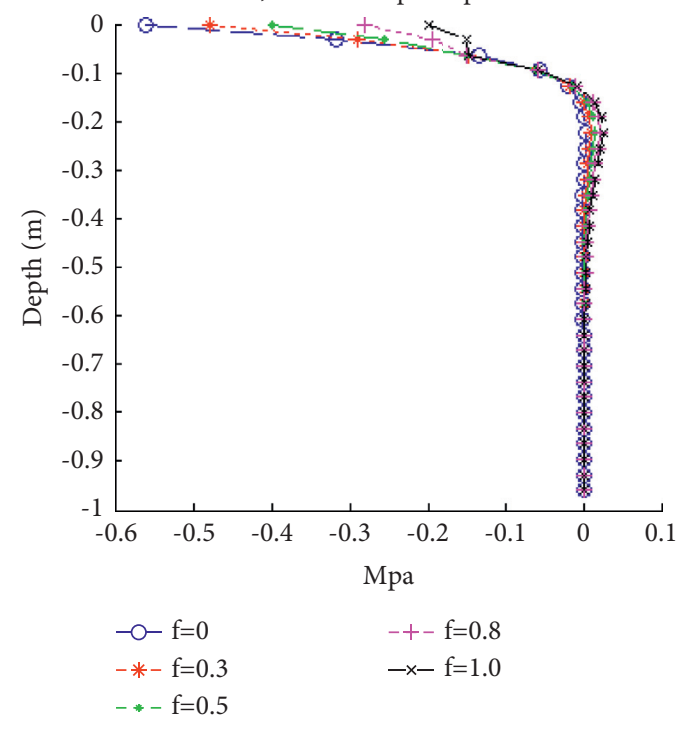

(a)

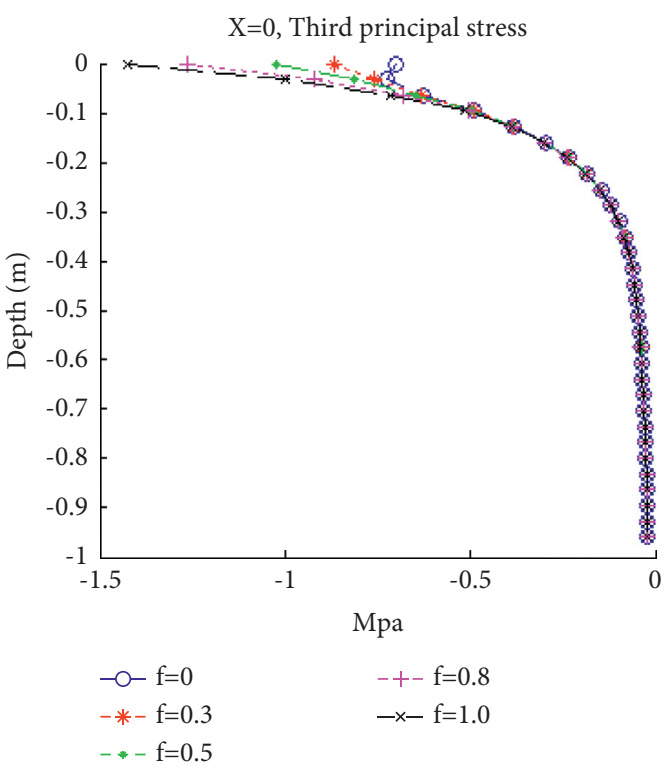

(b)

FIgURE 13: Continued. 


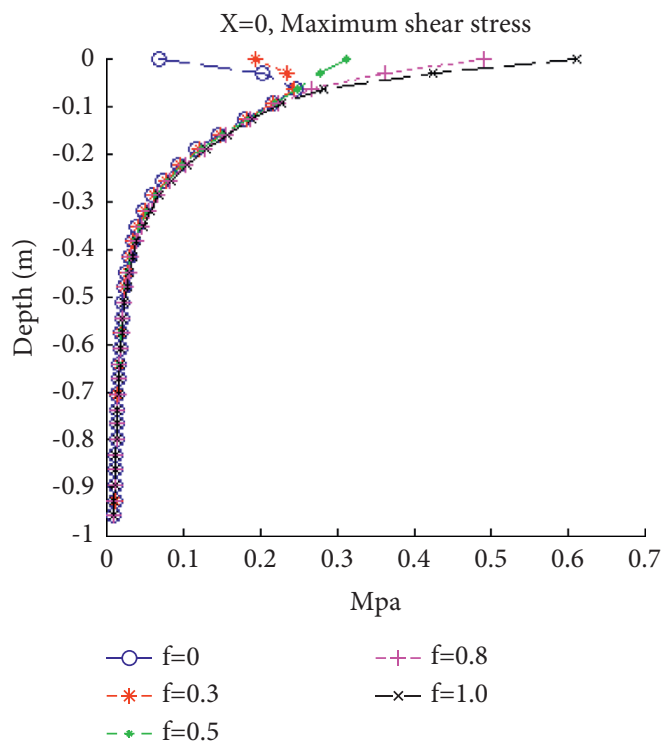

(c)

Figure 13: Calculation result of center point principal stress of single circular load in $z$-axis $(x=0)$. (a) Calculation result of center point maximum principal stress of single circular load in $z$-axis $(x=0)$. (b) Calculation result of center point third primary stress of single circular load in $z$-axis $(x=0)$. (c) Calculation result of center point maximum shear stress of single circular load in $z$-axis $(x=0)$.

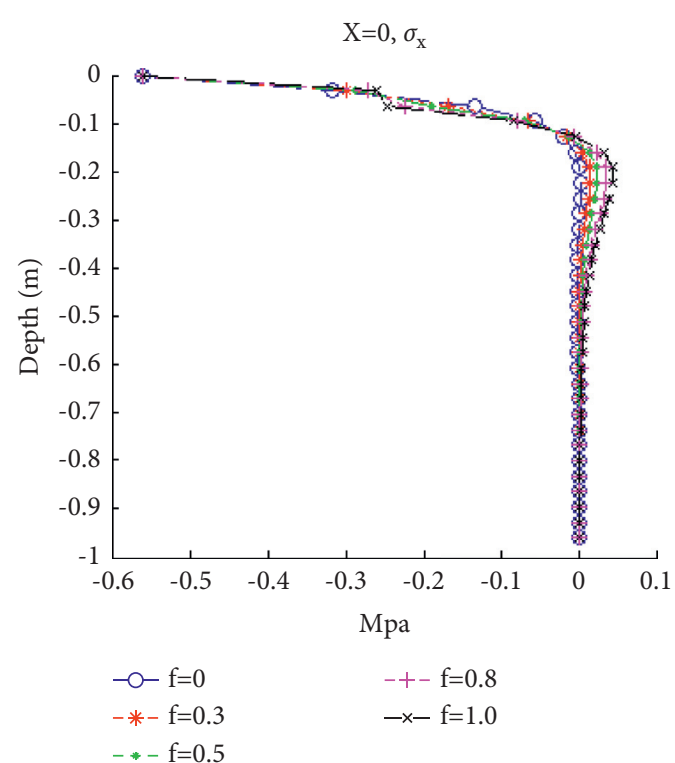

(a)

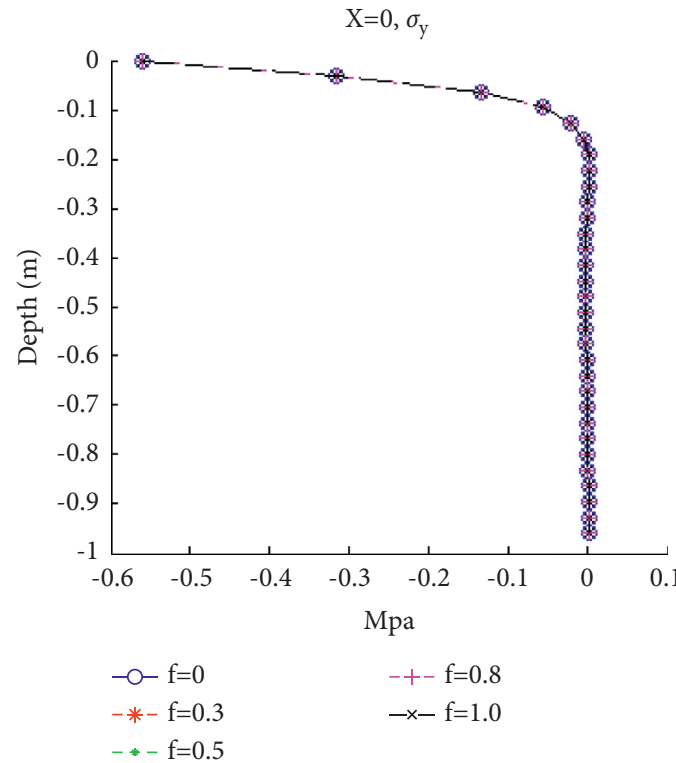

(b)

FIGURE 14: Continued. 


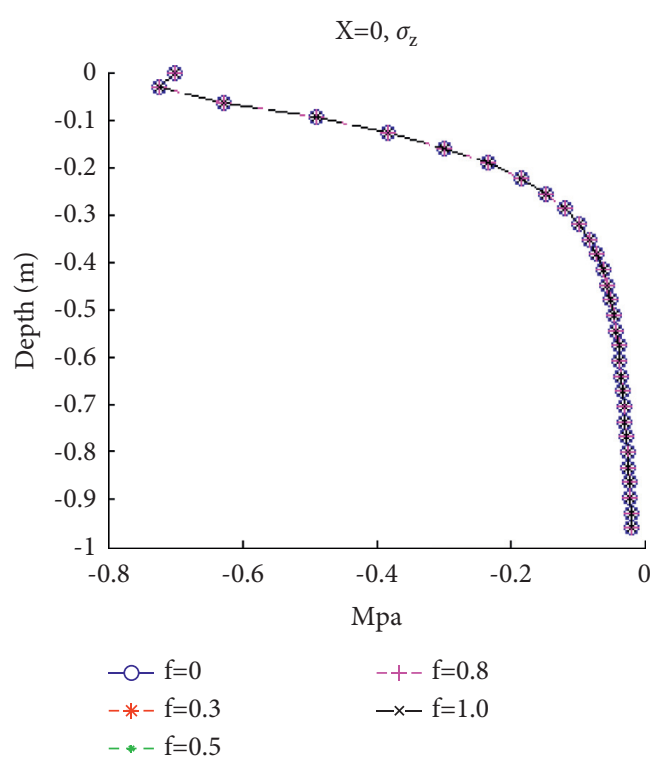

(c)

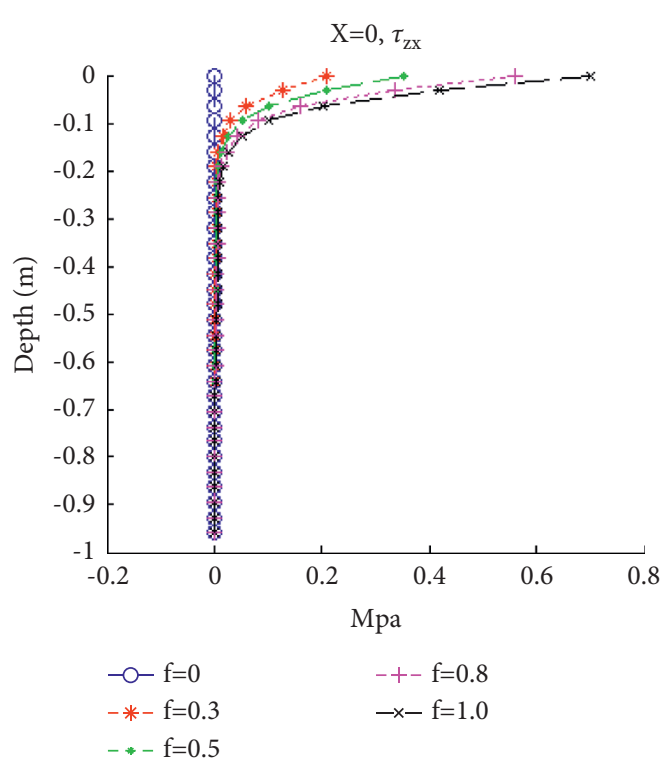

(d)

Figure 14: Calculation results of normal stress and shear stress in $z$-axis $(x=0)$ at center point of single circular load. (a) Calculation results of normal stress $\sigma_{x}$ in $z$-axis $(x=0)$ at center point of single circular load. (b) Calculation results of normal stress $\sigma_{y}$ in $z$-axis $(x=0)$ at center point of single circular load. (c) Calculation results of normal stress $\sigma_{z}$ in $z$-axis $(x=0)$ at center point of single circular load. (d) Calculation results of shear stress $\tau_{z x}$ in $z$-axis $(x=0)$ at center point of single circular load.

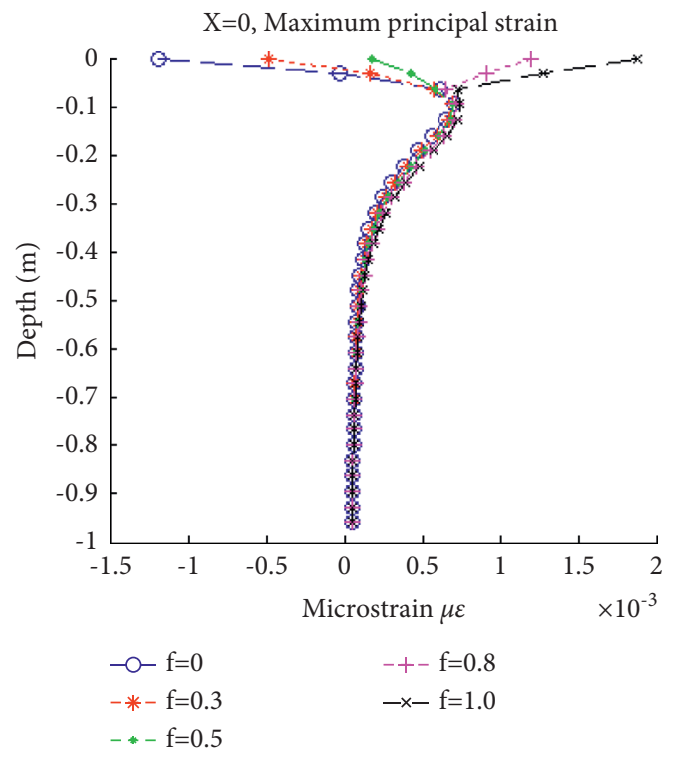

(a)

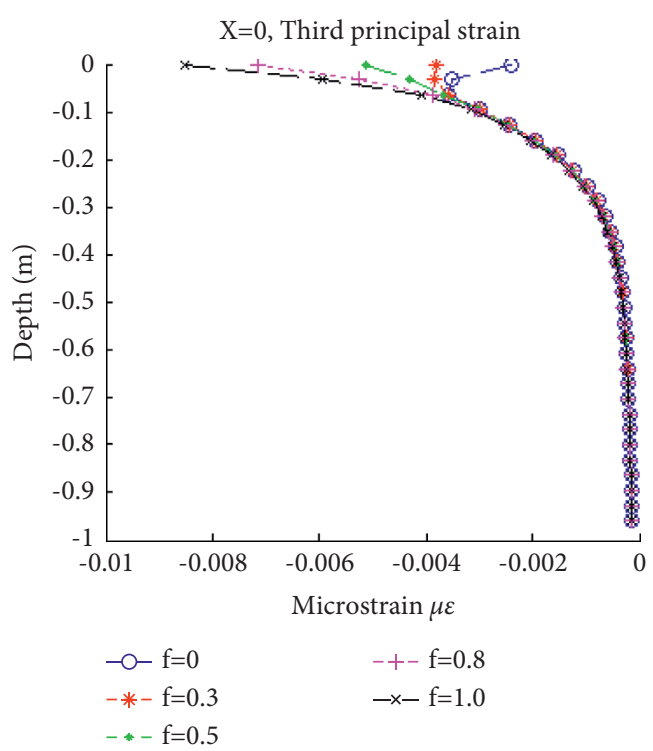

(b)

FIGURE 15: Calculation results of principal strain of $z$-axis $(x=0)$ at center point of single circular load. (a) Calculation results of maximum principal strain of $z$-axis $(x=0)$ at center point of single circular load. (b) Calculation results of third principal strain of $z$-axis $(x=0)$ at center point of single circular load.

\section{Conclusions}

This study proposed an asymmetric finite element numerical model approach to predict the internal stress, strain, and displacement of the elastic half-space structure under different friction coefficients, and the internal mechanics of the pavement structure is analyzed under the condition that the antiskid performance of the pavement is attenuated. The main contributions and conclusions are as follows:

(1) With the attenuation of the friction coefficient, when $Z=0$, the distribution law of stress, strain, and 
displacement of the pavement structure remains unchanged

(2) When the friction coefficient is 0 or 0.3 , as the depth increases, the maximum principal strain on the $z$ axis gradually transitions from compressive strain to tensile strain, and the maximum shear stress and the third principal strain both increase first and then decrease

(3) When the friction coefficient is 0.5 , with the increase of depth, the maximum principal strain value on the $z$-axis first increases and then decreases, and the maximum shear stress and the third principal strain decrease monotonically

(4) When the friction coefficient is 0.8 or 1.0 , both the maximum principal strain and the third principal strain on the $z$-axis monotonically decrease with the increase of depth

(5) With the attenuation of the friction coefficient, the horizontal displacement inside the pavement structure gradually decreases, the vertical displacement inside the pavement structure generally increases, and the maximum principal stress inside the pavement structure gradually decreases

(6) The area, depth, and tensile stress of the tension zone decrease within $20 \mathrm{~cm}$ from the load circle surface, and the maximum shear stress and maximum principal strain inside the pavement structure within the load circle gradually decrease, but the influence range becomes larger

Due to the limitations of the epidemic and current conditions, the design thresholds of pavement skid resistance and the experimental verification of the model need to be further studied.

\section{Data Availability}

The data used to support the findings of this study are available from the corresponding author upon request.

\section{Conflicts of Interest}

The authors declare that there are no conflicts of interest regarding the publication of this paper.

\section{Acknowledgments}

The authors are thankful for the financial support received from the Science and Technology Project of Science and Technology Department of Henan Province (Grant no. 202102310582), Key scientific research project of Xuchang University (Grant no. 2021ZD005), and Horizontal project of Xuchang University in 2021 (Grant no. 2021HX146).

\section{References}

[1] X. Huang and B. Zheng, "Research status and progress for skid resistance performance of Asphalt pavements," China Journal of Highway and Transport, vol. 32, no. 4, pp. 32-49, 2019.
[2] M. Kane, L. Artamendi, and T. Scarpas, "Long-term skid resistance of asphalt surfacings:correlation between wehner-schulze friction values and the mineralogical composition of the aggregates," Wear, vol. 303, no. 1/2, pp. 235-243, 2013.

[3] A. Najaf and H. Saeid, "Statistical analysis of variables affecting tire - pavement friction," International Journal of Pavement Research and Technology, vol. 14, no. 3, pp. 378384, 2020.

[4] Y. Han, Y. Zhao, J. Jiang, F. Ni, and X. Zhao, "Effects of design parameters and moisture conditions on interface bond strength between thin friction course (TFC) and underlying asphalt pavements," Construction and Building Materials, vol. 269, Article ID 121347, 2021.

[5] D. Yun, L. Hu, and C. Tang, "Tire-road contact area on asphalt concrete pavement and its relationship with the skid resistance," Materials, vol. 13, no. 3, p. 615, 2020.

[6] C. Dong, L. Zhou, and L. Chen, "Study on the stress response of tire pavement based on different driving conditions," Highway Engineer, vol. 43, no. 6, pp. 146-150, 2018.

[7] X. Huang, Q. Dai, and K. Ping, "Numeric analysis of friction contact between tread and flexible pavement," Journal of Highway and Transportation Research and Development, vol. 25, no. 1, pp. 16-20, 2008.

[8] J. R. Cho, H. W. Lee, J. S. Sohn, G. J. Kim, and J. S. Woo, "Numerical investigation of hydroplaning characteristics of three-dimensional patterned tire," European Journal of Mechanics - A: Solids, vol. 25, no. 6, pp. 914-926, 2006.

[9] K. Anupam, T. Tang, C. Kasbergen, A. Scarpas, and S. Erkens, "3-D thermomechanical tire-pavement interaction model for evaluation of pavement skid resistance," Transportation Research Record: Journal of the Transportation Research Board, vol. 2675, no. 3, pp. 65-80, 2021.

[10] D. Li, Simulation Research on Anti-sliding Performance Based on Tire-Surface Contact Characteristics, South China University of Technology, Guang zhou, China, 2020.

[11] M. Guo, Research on Mechanical Behavior of Asphalt Pavement Structure under Complex Heavy Loads, Wuhan University of Technology, Wuhan, China, 2021.

[12] L. Hao, Finite Element Simulation and Measurement of TirePavement Contact State Based on Pavement Texture, Chang'an University, Xi'an, China, 2021.

[13] Y. Yao, J. Li, J. Ni, C. Liang, and A. Zhang, "Effects of gravel content and shape on shear behaviour of soil-rock mixture: experiment and DEM modelling," Computers and Geotechnics, vol. 141, no. 1, Article ID 104476, 2022.

[14] J. Li, J. Zheng, Y. Yao, J. Zhang, and J. Peng, "Numerical method of flexible pavement considering moisture and stress sensitivity of subgrade soils," Advances in Civil Engineering, vol. 2019, Article ID 7091210, 10 pages, 2019.

[15] B. N. J. Persson, O. Albohr, U. Tartaglino, A. I. Volokitin, and E. Tosatti, "On the nature of surface roughness with application to contact mechanics, sealing, rubber friction and adhesion," Journal of Physics: Condensed Matter, vol. 17, no. 1, pp. R1-R62, 2005.

[16] K. Matsuda, D. Hashimoto, and K. Nakamura, "Real contact area and friction property of rubber with two-dimensional regular wavy surface," Tribology International, vol. 93, pp. 523-529, 2016.

[17] B. Song and S. Yan, "Relationship between the real contact area and contact force in pre-sliding regime," Chinese Physics B, vol. 26, no. 7, Article ID 74601, 2017. 
[18] S. Wu, H. Chen, J. Zhang, and Z. Zhang, "Effects of interlayer bonding conditions between semi-rigid base layer and asphalt layer on mechanical responses of asphalt pavement structure," International Journal of Pavement Research and Technology, vol. 10, no. 3, 2017.

[19] People's Communications Press, Industry Standard of the People's Republic of China. JTG D50-2017 Design Code for Highway Asphalt Pavement, People's Communications Press, Beijing, China, 2017.

[20] K. Wang, Mechanical Analysis and Calculation of Layered Elastic System, pp. 33-35, Science Press, Beijing, China, 2009. 